\title{
Design and Analysis of a New Magnetorheological Damper for Generation of Tunable Shock-Wave Profiles
}

\author{
Jong-Seok Oh, ${ }^{1}$ Tae-Hoon Lee, ${ }^{2}$ and Seung-Bok Choi $\mathbb{D}^{2}$ \\ ${ }^{1}$ Division of Mechanical and Automotive Engineering, Kongju National University, Chungnam 31080, Republic of Korea \\ ${ }^{2}$ Department of Mechanical Engineering, Smart Structures and Systems Laboratory, Inha University, Incheon 22212, Republic of Korea
}

Correspondence should be addressed to Seung-Bok Choi; seungbok@inha.ac.kr

Received 26 August 2017; Accepted 20 December 2017; Published 18 January 2018

Academic Editor: Daewon Kim

Copyright (C) 2018 Jong-Seok Oh et al. This is an open access article distributed under the Creative Commons Attribution License, which permits unrestricted use, distribution, and reproduction in any medium, provided the original work is properly cited.

A new impact testing system with an integrated magnetorheological (MR) damper is proposed, and its dynamic characteristics are analyzed. The testing system consists of a velocity generator, impact mass, test mass, spring, and MR damper. In order to tune the dual shock-wave profile, a dynamic model was constructed, and the appropriate design parameters of the MR damper were then determined to produce the required damping force. Following this, an impact testing system was constructed to evaluate the design analysis and field-dependent dual shock-wave profiles. The experimental results of impact test showed that the dual shock-wave profile can be altered by changing the intensity of the magnetic field.

\section{Introduction}

The components of submarines and other naval vessels are often damaged by shock-waves owing to noncontact underwater explosions (UNDEX) during wartime. Thus, impact tests are conducted to verify shock survivability or the ability of installations to withstand shock loading. To specify the requirements of impact tests, the US formulated military specification MIL-S-901D in 1989 [1]. Based on MILS-901D, impact tests are categorized as light- ( 550 pounds), medium- ( 7,400 pounds), and heavy-weight (7,400 pounds $\sim)$. The light- and medium-weight impact tests are performed using a shock machine, and heavy-weight tests are performed using a large floating shock platform and an UNDEX. These methods have several drawbacks (high cost, low efficiency, and environmental damage), and it is often recommended that heavy-weight tests should be conducted using the shock machine method.

Several methods have been proposed to solve this problem. Zhaodong et al. [2] proposed a dual-wave shock test machine to simulate an UNDEX and test the shock survivability of shipboard equipment. Wang et al. [3] studied a vertical heavy-weight shock test machine. Mathematical modeling and a mechanistic analysis verified that the proposed test machine can produce shock acceleration wave profiles consistent with the MIL-S-901D criteria (via computer simulation). Kim et al. [4-6] implemented dynamic design analysis for heavy dual shock generation systems. Their results and design analysis showed that the properties of the system components such as the spring and damping coefficients were correctly determined. However, the proposed dual-wave shock testing machines are still being constructed.

Many attempts to construct test systems must contend with difficulties such as the controllability of dual shock-wave profiles and dissipation of impact energy over short time periods. In this paper, we propose a heavy-weight impact testing machine equipped with a controllable magnetorheological (MR) damper. By applying a controllable MR damper, the generated acceleration profile can be tuned and the impact energy can be effectively dissipated. It is generally known that MR fluid is a smart material whose rheological properties can be altered by controlling magnetic field. Thus, many methods for energy dissipation have been proposed. Kim et al. [7, 8] evaluated the ride quality of a railway vehicle featuring an MR damper via roller rig and railway field tests, Stone and Cebon [9] evaluated the vibration control performance of an MR damper on heavy vehicles, and Yang et al. [10] proposed a large-scale MR damper to reduce the vibration for civil 
engineering applications. These studies were implemented on low-velocity and low-frequency semiactive applications; however, in severe conditions that produced high-impact load and velocity, the MR damper did not perform well.

Recently, new prediction models for dynamic behavior under high velocity and high frequency conditions have been proposed $[11,12]$. To account for the behavior of MR damper at high shear rates, Lee et al. [11] used the Herschel-Bulkley shear model and Mao et al. [12] used a nonlinear Bingham model based on loss factor and hydromechanical analysis. Ahmadian et al. [13-15] studied an MR impact damper in gun recoil dynamics and free-flight drop test facilities. Browne et al. [16] also evaluated the impact damping performance of an MR damper. Although these works focused on the dynamic behavior of MR impact dampers, the maximum damping force range of their proposed MR dampers was relatively low [11-16].

In this work, the dynamic characteristics of an MR impact damper are analyzed for high-impact energy dissipation. By using an MR impact damper, the desired dual shockwave profile can be easily tuned by varying the input current to the MR damper and other physical conditions such as mass, spring constants, and input velocity. Thus, the main contribution of this work is the proposal of a novel impact testing machine using an MR damper for the heavy-weight components of submarines and other naval vessels. First, the impact test system is introduced, and then the dynamic analysis is undertaken. Based on dynamic models, the proper physical coefficients of the test system are determined to generate heavy dual shock-wave profiles. To predict the damping force of the MR damper, a mathematical model is derived based on the Bingham plastic axisymmetric model. Using the geometrical dimensions obtained from the numerical analysis performed with the mechanical model, FE (finite element) magnetic circuit analysis is performed via computer simulation. Then, the damping force of MR damper and input condition such as current is calculated from the FE analysis results and geometrical dimensions. For evaluating the field-dependent dual shock-wave profiles, an impact testing machine system is constructed. By measuring the acceleration on the test mass and damping force of the MR damper, it is confirmed that several dual shock-wave profiles can be obtained by tuning the input conditions of the proposed impact testing system such as input current to MR damper.

\section{Impact Testing System}

In contrast with MIL-S-901, which requires full-scale submarine or naval vessel testing for heavy-weight components, $\mathrm{BV}-43 / 85$ (developed in Germany) requires that the shock loadings be applied to components that are directly attached to surface shipboard equipment or submarines [1, 17-20]. In $\mathrm{BV}-43 / 85$, a double half-sine acceleration profile is used to represent the shock loading caused by an UNDEX. As shown in Figure 1, the acceleration profile consists of three parts. The positive half-wave (Part I) shows the effect of the magnitude of impact, and the negative half-wave (Part II) and Part III are related to the energy dissipation system. In Figure 1, the

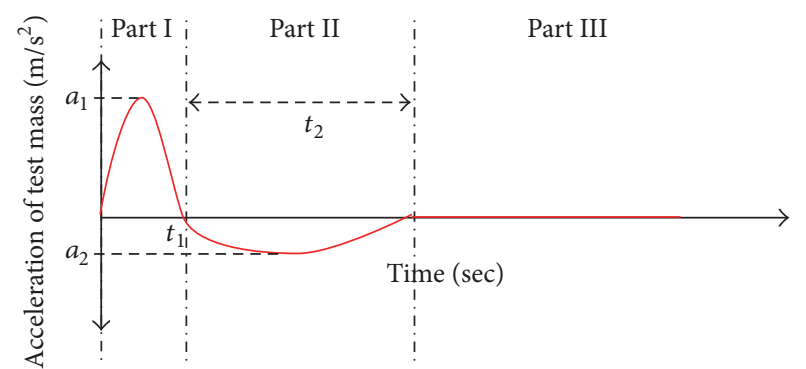

FIGURE 1: Shape of dual shock-wave profile in BV-043/85.

magnitude of acceleration in Part II is relatively lower than that of Part I and the magnitude of residual vibration (Part III) is zero.

A hydraulic impact testing system is developed to generate the dual shock-wave profile, as shown in Figure 2. The test facility comprises a hydraulic velocity generator, impact mass, polyurethane spring, test mass, air spring, and MR damper. The specimen is attached at the test mass. In the impact testing machine, the hydraulic velocity generator accelerates the impact mass, and the impact mass then strikes the polyurethane spring and test mass with a uniform motion. The high-impact load and velocity are then applied to the air spring and MR damper, which were located between the test mass and a fixed wall. The MR damper is used to reduce the transmitted reaction force (Part II) and residual vibration (Part III). In other words, the generation of a shockwave profile, particularly for Parts II and III, is the primary function of the MR damper.

The method for determining the input velocity of the hydraulic velocity generator and the relation of impact and test mass is represented in Figure 3; the equation of motion during contact time is expressed as follows [4]:

$$
\begin{aligned}
& m_{1} \ddot{x}_{1}+k_{1}\left(x_{1}-x_{2}\right)=0, \\
& m_{2} \ddot{x}_{2}+k_{1}\left(x_{2}-x_{1}\right)=0 .
\end{aligned}
$$

Since the 1st impact force is very large and contact time is very short, the motion of the air spring and MR damper is neglected during 1st pulse generation. As the initial conditions are $x_{1}(0)=x_{2}(0)=\dot{x}_{2}(0)=0, \dot{x}_{1}(0)=V_{g}$, the acceleration of 1st pulse is expressed as

$$
\begin{aligned}
\ddot{x}_{2}(t) & =\frac{m_{1} \omega V_{g}}{m_{1}+m_{2}} \sin \omega t, \\
\omega & =\sqrt{\frac{\left(m_{1}+m_{2}\right) k_{1}}{m_{1} m_{2}}}=\frac{\pi}{\tau_{1}} .
\end{aligned}
$$

Supposing that the maximum acceleration, $a_{1}$, and duration time of 1st pulse wave, $t_{1}$, are given, the input velocity and the spring constant of polyurethane spring are obtained from 


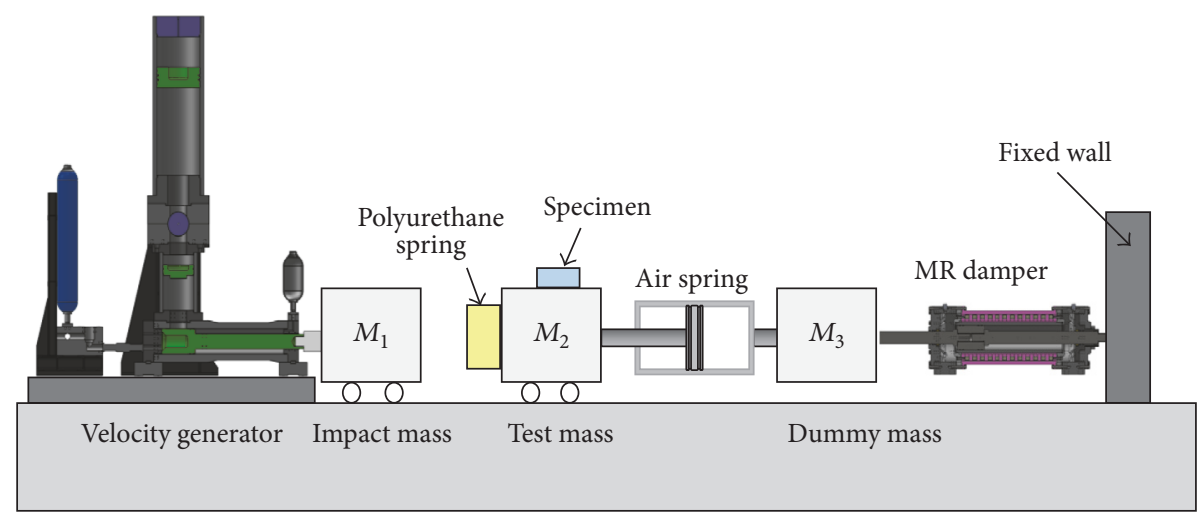

(a) Simplified mechanical model

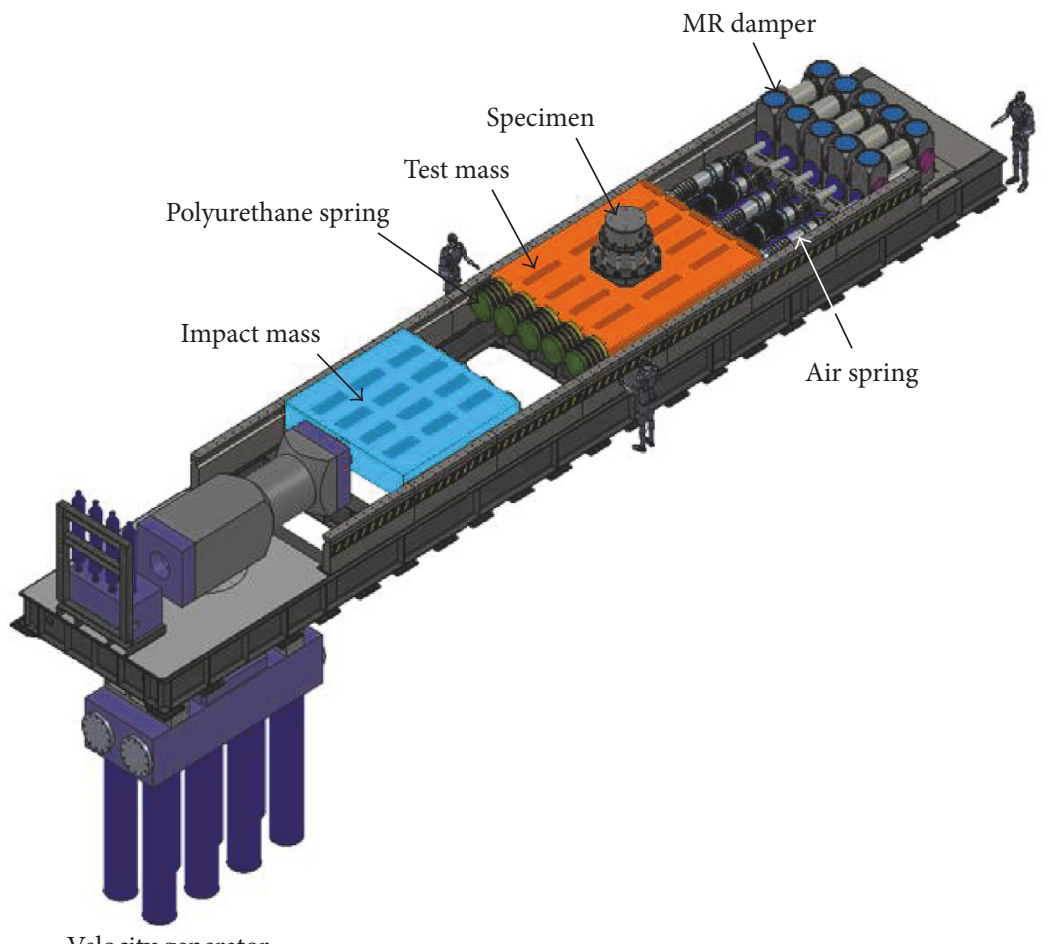

Velocity generator

(b) Experimental apparatus

FIGURE 2: Schematic of the impact testing machine system.

(2). To predict the 2nd pulse wave, the dynamic modeling represented in Figure 4 is implemented as follows:

$$
\begin{aligned}
m_{2} \ddot{x}_{2}+k_{2}\left(x_{2}-x_{3}\right) & =0, \\
m_{3} \ddot{x}_{3}+c \dot{x}_{3}+k_{2}\left(x_{3}-x_{2}\right) & =0,
\end{aligned}
$$

where $x_{2}(0)=x_{0}, \dot{x}_{2}(0)=V_{t}$.

$m_{3}$ is the dummy mass of the air spring. Using the Laplace transform, the responses of the test and dummy masses are expressed as

$$
\begin{aligned}
& s^{2} X_{2}(s)=\frac{m_{2} V_{t} s\left(m_{3} s^{2}+c s+k_{2}\right)}{D(s)}, \\
& s^{2} X_{3}(s)=\frac{m_{2} V_{t} k_{2} s}{D(s)}
\end{aligned}
$$

where $D(s)=m_{2} m_{3} s^{3}+m_{2} c s^{2}+\left(m_{2}+m_{3}\right) k_{2} s+c k_{2}$.

Suppose that $D(s)$ has one real and two complex roots and can be expressed as

$$
\begin{aligned}
D(s) & =m_{2} m_{3} s^{3}+m_{2} c s^{2}+\left(m_{2}+m_{3}\right) k_{2} s+c k_{2} \\
& =m_{2} m_{3}(s+\alpha)\left(s^{2}+2 \varsigma \omega_{n} s+\omega_{n}{ }^{2}\right) .
\end{aligned}
$$




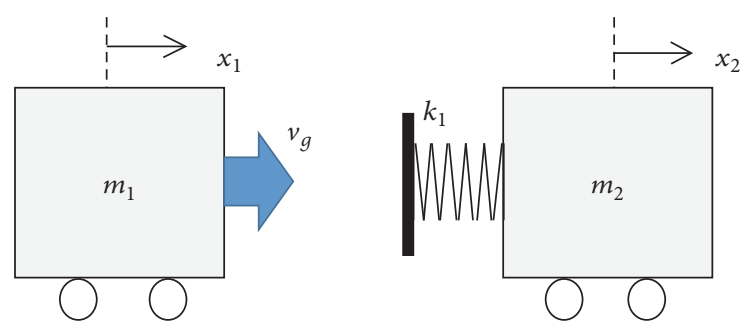

(a) Before impact

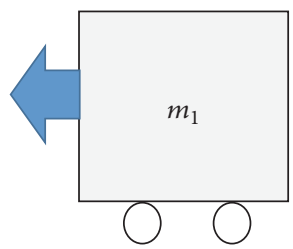

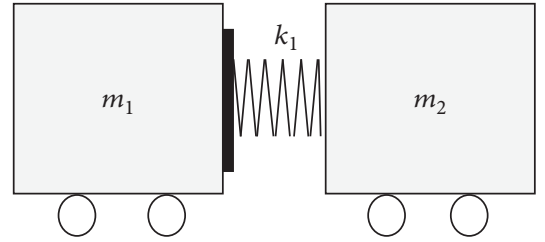

(b) During impact

(c) After impact

FIGURE 3: Simplified model of impact testing system for 1st shock-wave.

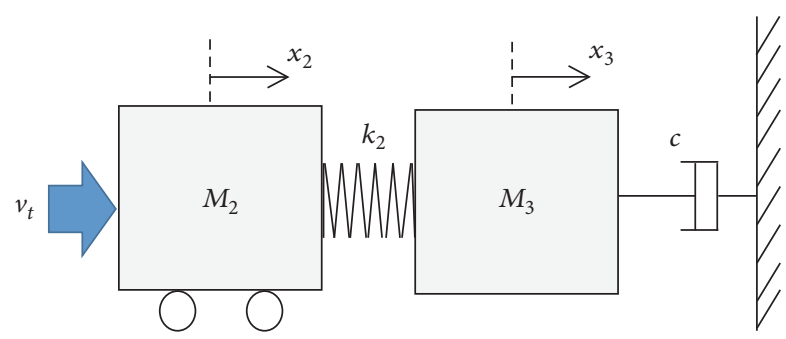

FIGURE 4: Simplified model of impact testing system for 2nd shockwave.

Following this, the 2nd pulse wave is obtained as follows [6]:

$$
\begin{aligned}
& x_{2}(t) \cong-\frac{b}{\omega_{n}^{2} \sqrt{1-\varsigma^{2}}} e^{-\varsigma \omega_{n} t} \sin \left(\sqrt{1-\varsigma^{2}} \omega_{n} t\right), \\
& \quad \text { where } b=\frac{\omega_{n}^{2}(\alpha-a)}{\alpha}, a=\sqrt{\frac{2 \varsigma \omega_{n}+\alpha-c / m_{3}}{2}} .
\end{aligned}
$$

To determine the physical coefficients of the impact testing system, the desired dual shock-wave profile was chosen according to BV-43/84 criteria, as shown in Table 1 [7]. To evaluate the performance of the MR damper, the 1st shock-wave was fixed, and the input and spring velocities of the polyurethane spring remained constant. The impact, test, specimen, and dummy masses were $10,000 \mathrm{~kg}, 11,000 \mathrm{~kg}$, $5,000 \mathrm{~kg}$, and $8,000 \mathrm{~kg}$, respectively. The spring constants and damping properties of the MR damper were calculated based on (2) and (6). For each 2nd pulse wave profile, there were many solutions of $k_{2}$ and $c$. Of these, the proper spring constant and damping constant were determined to meet five shapes of the 2nd pulse and demonstrate the control performance of the MR damper. In other words, using same $k_{2}$ and $c$ for all test conditions, 2nd pulses were tuned by controlling the damping force of the MR damper; the resulting values are shown in Table 2. From Table 2, the maximum required viscous damping force is $300 \mathrm{kN}$ at $2 \mathrm{~m} / \mathrm{sec}$, maximum controllable damping force is $518.3 \mathrm{kN}$, and total damping force is $818.3 \mathrm{kN}$.

\section{Design of MR Damper}

In this experiment, a new high-impact MR damper was designed, as shown in Figure 5. The MR damper consists of piston, coil, and outer housing. The annular duct is placed between coil and outer housing. During piston movements induced from a high-impact event, the piston moved at a high velocity and the MR fluid flowed through the outer annular duct. Since the pressure drop is caused from fluid flow, viscous damping force is generated. The advantage of MR damper is that damping force can be increased by applying the current input to coil. During MR fluid flow, the yield stress of MR fluid is amplified according to magnetic field. It is generally known that magnetic field is generated on both sides of the coil. By applying multi-magnetic cores, the active length which is calculated as total length of duct minus the total coils length was increased. In other words, the total damping force is bigger than the case of MR damper with single core and same design parameters. With the use of 21 magnetic poles and the consequent increase in the active length, it was identified that the proposed MR damper could provide a more effective control performance.

Several shear stress models of MR fluid were used to predict the behavior of MR damper [11-15, 21, 22]. Among them, nonlinear Bingham model showed good performance in shock absorber application [12, 21, 22]. Accordingly, Bingham model was used in this work. Based on the Bingham model, the total shear stress of MR fluid can be expressed as follows:

$$
\tau_{r x}=\tau_{y}(H)+\eta \dot{\gamma}=\tau_{y}(H)+\eta \frac{d u_{x}(r)}{d r},
$$




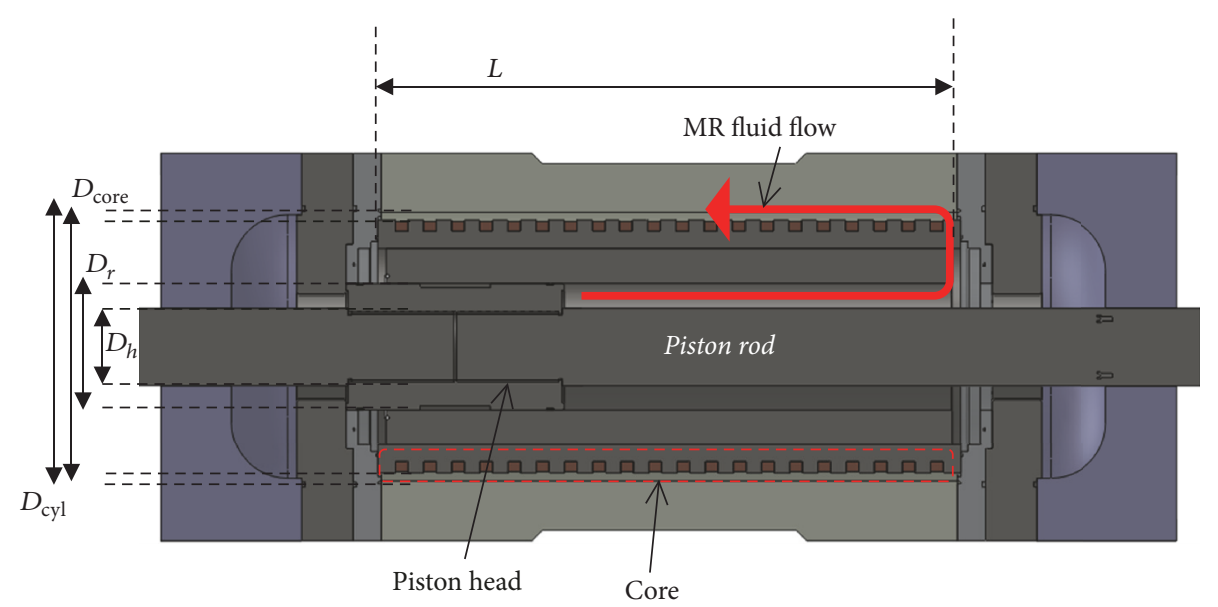

FIGURE 5: Design configuration of the proposed MR damper.

TABLE 1: Desired profiles of dual shock-waves.

\begin{tabular}{|c|c|c|c|c|c|c|c|}
\hline $\begin{array}{l}\text { Test } \\
\text { number }\end{array}$ & $\begin{array}{l}\text { Peak acceleration, } a_{1} \\
\left(\mathrm{~m} / \mathrm{s}^{2}\right)\end{array}$ & $\begin{array}{c}\text { Duration time, } t_{1} \\
(\mathrm{sec})\end{array}$ & $\begin{array}{l}\text { Peak acceleration, } a_{2} \\
\left(\mathrm{~m} / \mathrm{s}^{2}\right)\end{array}$ & $\begin{array}{c}\text { Duration time, } t_{2} \\
(\mathrm{sec})\end{array}$ & $m_{1}(\mathrm{~kg})$ & $m_{2}(\mathrm{~kg})$ & $m_{3}(\mathrm{~kg})$ \\
\hline Test \#1 & 750 & 0.0100 & -125 & 0.0520 & 10000 & 11000 & 8000 \\
\hline Test \#2 & 750 & 0.0100 & -135 & 0.0540 & 10000 & 11000 & 8000 \\
\hline Test \#3 & 750 & 0.0100 & -140 & 0.0555 & 10000 & 11000 & 8000 \\
\hline Test \#4 & 750 & 0.0100 & -145 & 0.0570 & 10000 & 11000 & 8000 \\
\hline Test \#5 & 750 & 0.0100 & -150 & 0.0585 & 10000 & 11000 & 8000 \\
\hline
\end{tabular}

TABLE 2: Calculated physical coefficients for the impact testing machine.

\begin{tabular}{lcccccc}
\hline Test number & $V_{g}(\mathrm{~m} / \mathrm{s})$ & $k_{1}(\mathrm{MN} / \mathrm{m})$ & $k_{2}(\mathrm{MN} / \mathrm{m})$ & $c(\mathrm{kN} \cdot \mathrm{s} / \mathrm{m})$ & $F_{\mathrm{MR}}(\mathrm{kN})$ & Input current $(\mathrm{A})$ \\
\hline Test \#1 & 4.97 & 516.9 & $17 \mathrm{MN} / \mathrm{m}$ & $150 \mathrm{kN} \cdot \mathrm{s} / \mathrm{m}$ & $150 \mathrm{kN} \cdot \mathrm{s} / \mathrm{m}$ & 171.3 \\
Test \#2 & 4.97 & 516.9 & $17 \mathrm{MN} / \mathrm{m}$ & $170 \mathrm{kN} \cdot \mathrm{s} / \mathrm{m}$ & 295.1 & 1 \\
Test \#3 & 4.97 & 516.9 & $17 \mathrm{MN} / \mathrm{m}$ & $150 \mathrm{kN} \cdot \mathrm{s} / \mathrm{m}$ & 400.6 & 2 \\
Test \#4 & 4.97 & 516.9 & $17 \mathrm{MN} / \mathrm{m}$ & $150 \mathrm{kN} \cdot \mathrm{s} / \mathrm{m}$ & 518.3 \\
Test \#5 & 4.97 & 516.9 & $17 \mathrm{MN} / \mathrm{m}$ & & & 4 \\
\hline
\end{tabular}

where $\tau_{y}(H)$ is the yield stress as a function of the magnetic field; $\eta$ is the viscous coefficient of the MR fluid; and $\dot{\gamma}$ is the shear rate. An axisymmetric annular duct flow model was used to calculate the pressure gradient and damping force, as shown in Figure 6. $u_{x}(r)$ is the fluid velocity in annular duct and $x$ is the longitudinal coordinate. The governing equation of the duct flow model was derived by simplified Navier-Stokes equations with the assumptions that the flow was essentially axial and the effect of fluid inertia can be neglected $[10,23]$. Particularly, many researchers obtained reasonable results in shock application by neglecting the effect of fluid inertia in duct $[24,25]$

$$
\begin{aligned}
\frac{d}{d r} \tau_{r x}(r)+\frac{\tau_{r x}(r)}{r} & =\frac{d p}{d x}, \\
\tau_{r x}(r) & =\frac{1}{2} \frac{d p}{d x} r+\frac{C_{1}}{r},
\end{aligned}
$$

where $C_{1}$ is the integral constant. The boundary condition of annular duct is $u\left(R_{\text {core }}\right)=u\left(R_{\text {cyl }}\right)=0$. Based on (7), (8), and the boundary condition, the fluid velocity in region 1 was obtained as follows:

$$
\begin{aligned}
u_{x 1}(r)= & \frac{1}{4 \eta}\left(\frac{d p}{d x}\right)\left(r^{2}-R_{\text {core }}^{2}\right)+\frac{C_{1}}{\eta} \ln \frac{r}{R_{\text {core }}} \\
& -\frac{1}{\eta} \tau_{y}\left(r-R_{\text {core }}\right), \quad \text { where } R_{\text {core }} \leq r \leq r_{a} .
\end{aligned}
$$

Similar duct modeling analysis is applied to region 3. However, the shear rate in region 3 is $\dot{\gamma}=-d u_{x}(r) / d r$. At the center of duct, the absolute shear rates are the same and sign is different according to upper and lower directions. 


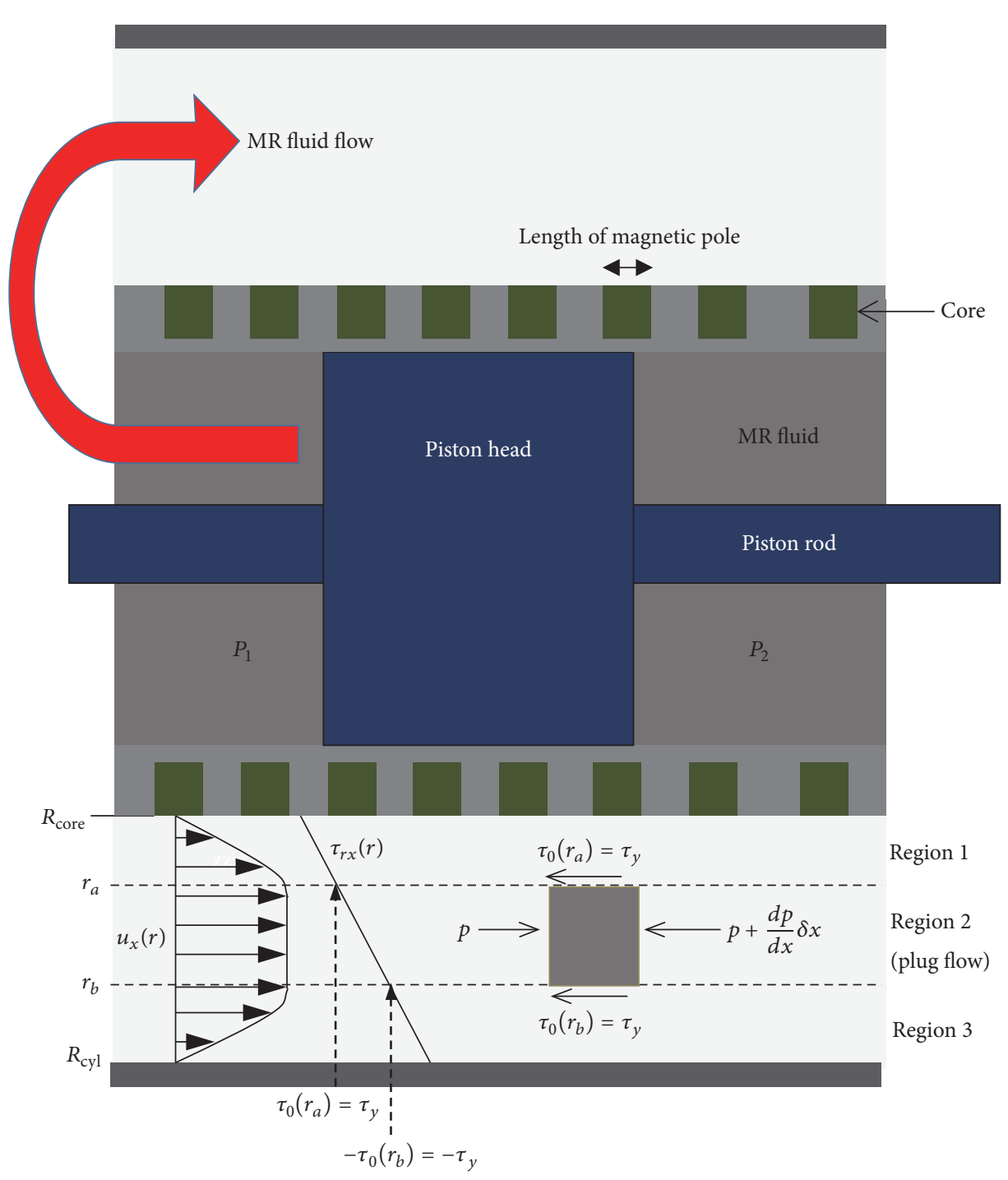

FIGURE 6: Incompressible viscous axisymmetric annular duct flow model.

Accordingly, the fluid velocity in region 3 was obtained as follows:

$$
\begin{aligned}
u_{x 3}(r)= & \int_{r}^{R_{\mathrm{cyl}}}-\frac{1}{\eta}\left[\frac{1}{2} \frac{d p}{d x} r+\frac{C_{1}}{r}+\tau_{y}\right] d r \\
= & \frac{1}{4 \eta}\left(\frac{d p}{d x}\right)\left(r^{2}-R_{\mathrm{cyl}}^{2}\right)+\frac{C_{1}}{\eta} \ln \frac{r}{R_{\mathrm{cyl}}} \\
& -\frac{1}{\eta} \tau_{y}\left(R_{\mathrm{cyl}}-r\right), \quad \text { where } r_{b} \leq r \leq R_{\mathrm{cyl}} .
\end{aligned}
$$

Since the shear stress in region 2 was less than the yield stress of the MR fluid, the flow velocity gradient was zero. Hence, the shear stress in region 2 can be expressed as follows:

$$
\begin{aligned}
& u_{x 2}(r) \\
& =\frac{1}{4 \eta}\left(\frac{d p}{d x}\right)\left(r_{a}{ }^{2}-R_{\text {core }}{ }^{2}\right)+\frac{C_{1}}{\eta} \ln \frac{r_{a}}{R_{\text {core }}}
\end{aligned}
$$

$$
\begin{aligned}
& -\frac{1}{\eta} \tau_{y}\left(r_{a}-R_{\text {core }}\right) \text { or } \frac{1}{4 \eta}\left(\frac{d p}{d x}\right)\left(r_{b}^{2}-R_{\mathrm{cyl}}^{2}\right) \\
& +\frac{C_{1}}{\eta} \ln \frac{r_{b}}{R_{\mathrm{cyl}}}-\frac{1}{\eta} \tau_{y}\left(R_{\mathrm{cyl}}-r_{b}\right),
\end{aligned}
$$

where $r_{a} \leq r \leq r_{b}$.

In order to obtain integral constant, $C_{1}$, the free body diagram of MR fluid in Figure 6 can be derived as follows:

$$
\begin{gathered}
\frac{d p}{d x} \pi\left(r_{b}^{2}-r_{a}^{2}\right) d x+2 \pi \tau_{y}\left(r_{b}+r_{a}\right) d x \\
=\frac{d p}{d x}\left(r_{b}-r_{a}\right)+2 \tau_{y}=0 .
\end{gathered}
$$

By integrating (8) and (12), $C_{1}$ can be expressed as follows:

$$
C_{1}=\frac{r_{b} r_{a}}{r_{b}-r_{a}} 2 \tau_{y}
$$


Equation (11) can be reexpressed as follows:

$$
\begin{gathered}
\frac{1}{4}\left(\frac{d p}{d x}\right)_{\mathrm{MR}}\left(R_{\mathrm{cyl}}^{2}-R_{\mathrm{core}}^{2}-r_{b}^{2}+r_{a}^{2}\right) \\
+\frac{r_{b} r_{a} \tau_{y}}{r_{b}-r_{a}} \ln \left(\frac{R_{\mathrm{cyl}} r_{a}}{R_{\mathrm{core}} r_{b}}\right) \\
+\tau_{y}\left(R_{\text {cyl }}+R_{\text {core }}-r_{b}-r_{a}\right) 0 .
\end{gathered}
$$

The total flow rate, $Q_{t}$, in the annular duct and the flow rate induced from piston movement can be expressed as follows:

$$
Q_{t}-\left(A_{h}-A_{r}\right) v_{p}=0
$$

where $v_{p}$ is the piston velocity. $A_{h}$ and $A_{r}$ are the crosssection areas of the piston head and piston rod, respectively. The total flow rate was reexpressed by the sum of the flow volumes of each region:

$$
\begin{aligned}
Q_{t}= & 2 \pi \int_{R_{\text {core }}}^{r_{a}}\left[u_{x 1}(r) r\right] d r+2 \pi \int_{r_{a}}^{r_{b}}\left[u_{x 2}(r) r\right] d r \\
& +2 \pi \int_{r_{b}}^{R_{\mathrm{cyl}}}\left[u_{x 3}(r) r\right] d r .
\end{aligned}
$$

The damping force of the MR damper, $F_{d}$, can be expressed as follows:

$$
F_{d}=P_{1}\left(A_{h}-A_{r}\right)-P_{2}\left(A_{h}-A_{r}\right)
$$

$P_{1}$ and $P_{2}$ are the pressures of upper and lower chambers, respectively. Due to pressure drop in annular duct, the pressures of upper and lower chamber are different. Also, damping force of MR damper which consisted of the controllable and viscous damping forces can be reexpressed as follows:

$$
\begin{aligned}
F_{d}= & F_{\mathrm{MR}}+F_{\eta} \\
= & \left(\frac{d p}{d x}\right)_{\mathrm{MR}}\left(L-L_{\text {pole }}\right)\left(A_{h}-A_{r}\right) \\
& +\left(\frac{d p}{d x}\right)_{\eta} L\left(A_{h}-A_{r}\right),
\end{aligned}
$$

where $(d p / d x)_{\mathrm{MR}}$ and $(d p / d x)_{\eta}$ are the pressure gradients induced from the MR effect and viscous force, respectively; and $L$ is the length of annular duct and $L_{\text {pole }}$ is the sum of the length of 21 magnetic poles. $(d p / d x)_{\mathrm{MR}}$ can be obtained using (14) and (15). In order to obtain $(d p / d x)_{\eta}$, the flow velocity of annular duct without magnetic field can be derived with $\tau_{r x}=\eta\left(d u_{x}(r) / d r\right)$ :

$$
\begin{array}{r}
u_{x}(r)=\frac{1}{4 \eta}\left(\frac{d p}{d x}\right)_{\eta}\left(r^{2}-R_{\text {core }}^{2}\right)+\frac{C_{2}}{\eta} \ln \frac{r}{R_{\text {core }}} \\
\text { where } C_{2}=-\frac{d p}{d x} \frac{\left(R_{\text {core }}^{2}-R_{\text {cyl }}^{2}\right)}{4 \ln \left(R_{\text {core }} / R_{\text {cyl }}\right)} .
\end{array}
$$

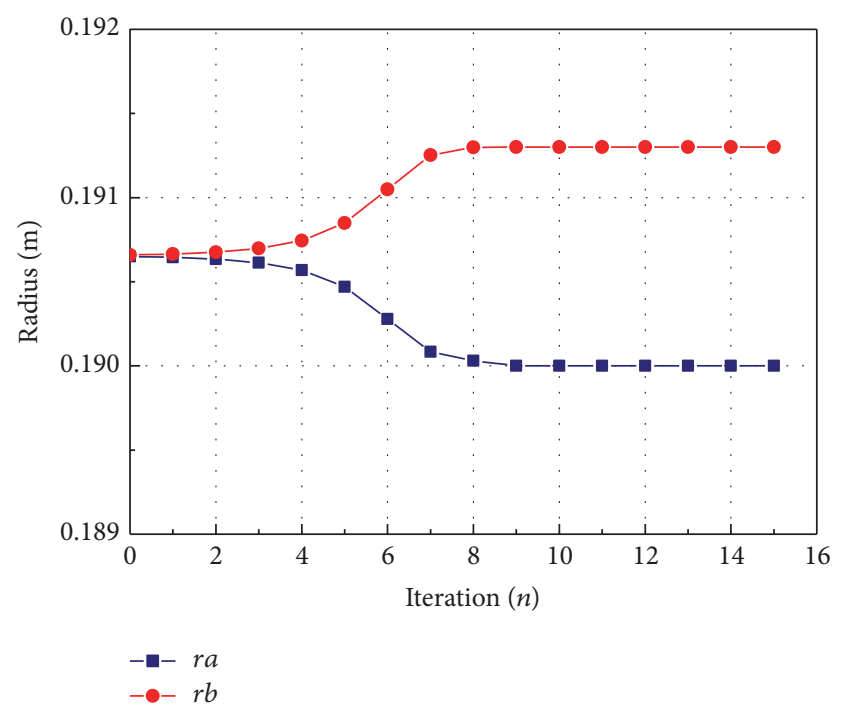

Figure 7: Optimized design parameters using Newton-Raphson method.

By substituting (19) for (15), the following equation was obtained:

$$
\begin{aligned}
& 2 \pi \int_{R_{\text {core }}}^{R_{\text {cyl }}}\left[u_{x}(r) r\right] d r-\left(A_{h}-A_{r}\right) v_{p} \\
& \quad=2 \pi \int_{R_{\text {core }}}^{R_{\text {cyl }}}\left[\frac{1}{4 \eta}\left(\frac{d p}{d x}\right)_{\eta}\left(r^{2}-R_{\text {core }}^{2}\right)\right. \\
& \left.+\frac{C_{2}}{\eta} \ln \frac{r}{R_{\text {core }}}\right] r d r-\left(A_{h}-A_{r}\right) v_{p}=0 .
\end{aligned}
$$

$(d p / d x)_{\eta}$ was obtained by calculating (20). $r_{a}$ and $r_{b}$ were obtained by applying the two-variable Newton-Raphson method:

$$
\left[\begin{array}{c}
r_{a, i+1} \\
r_{b, i+1}
\end{array}\right]=\left[\begin{array}{c}
r_{a, i} \\
r_{b, i}
\end{array}\right]-\left[\begin{array}{ll}
\frac{\partial g}{\partial r_{a}} & \frac{\partial g}{\partial r_{b}} \\
\frac{\partial w}{\partial r_{a}} & \frac{\partial w}{\partial r_{b}}
\end{array}\right]^{-1}\left[\begin{array}{l}
g\left(r_{a, i}, r_{b, i}\right) \\
w\left(r_{a, i}, r_{b, i}\right)
\end{array}\right]
$$

where $g\left(r_{a, i}, r_{b, i}\right)$ is (15); $w\left(r_{a, i}, r_{b, i}\right)$ is (14); and $i$ means the number of iterations. Figure 7 shows the final values as $r_{a}=0.19 \mathrm{~m}$ and $r_{b}=0.1913 \mathrm{~m}$. From the iteration results, it has been revealed that the thickness of regions 1 and 3 is theoretically almost zero. As previously mentioned, the maximum required MR damping force is $818.3 \mathrm{kN}$ at $2 \mathrm{~m} / \mathrm{s}$. In order to simplify the design procedure, maximum yield stress of MR fluid is assumed as $40 \mathrm{kPa}$. Using the above equations and repeated calculations, the damping force can be calculated using (15). The calculated controllable and viscous damping forces of the MR damper (at $2 \mathrm{~m} / \mathrm{s}$ ) are $504.9 \mathrm{kN}$ and $300.9 \mathrm{kN}$, respectively. As the predicted total damping force was $805.8 \mathrm{kN}$, the MR damper was manufactured with the design parameters in Table 3 . In addition, a magnetic flux analysis was performed to confirm that the magnetic circuit in the MR damper could generate a suitable magnetic field. 


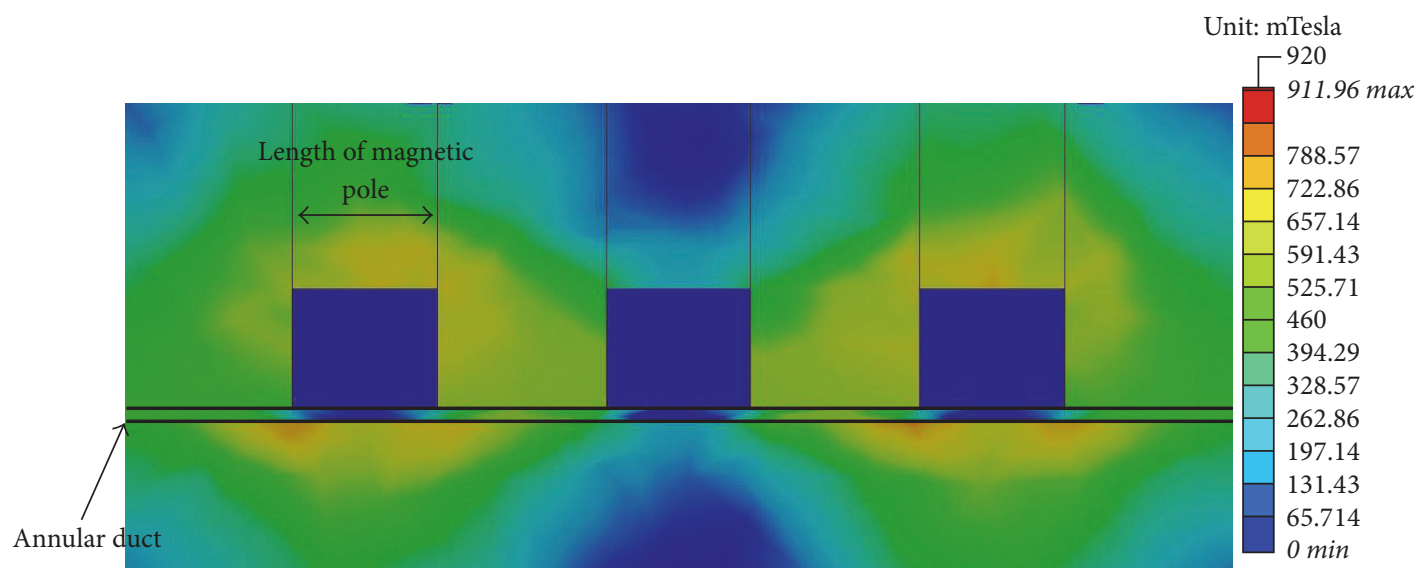

(a) Applied current: $2 \mathrm{~A}$

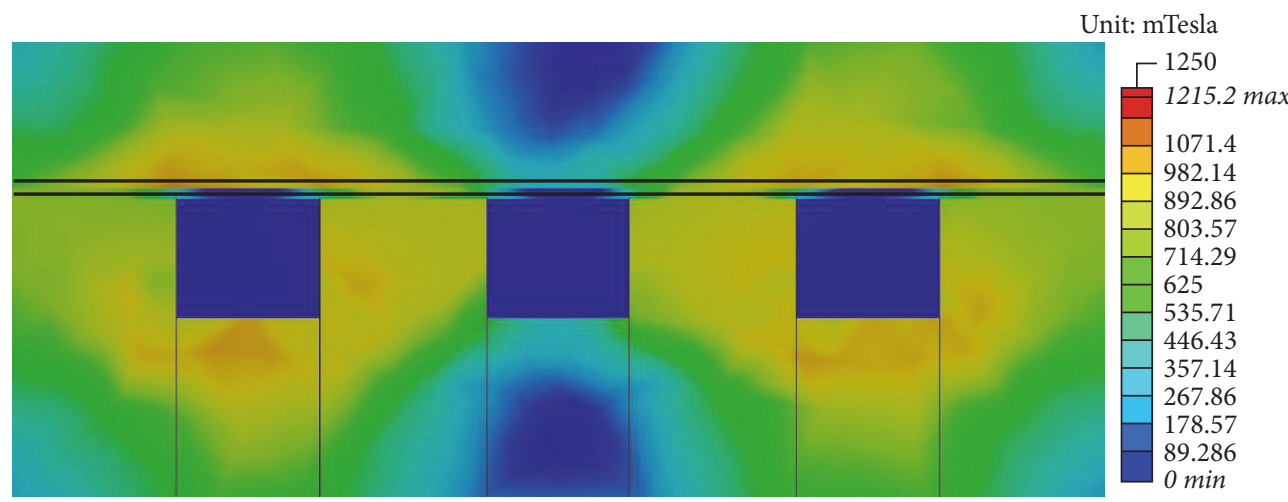

(b) Applied current: $4 \mathrm{~A}$

FIGURE 8: FEM result for magnetic circuit of the proposed MR damper.

TABLE 3: Geometric specifications of the MR impact damper.

\begin{tabular}{lcc}
\hline Specification & Symbol & Value \\
\hline Diameter of piston head & $D_{h}$ & $0.200 \mathrm{~m}$ \\
Diameter of piston rod & $D_{r}$ & $0.140 \mathrm{~m}$ \\
Magnetic core diameter & $D_{\text {core }}$ & $0.3800 \mathrm{~m}$ \\
Cylinder diameter & $D_{\text {cyl }}$ & $0.3826 \mathrm{~m}$ \\
Orifice gap size & $h$ & $0.0013 \mathrm{~m}$ \\
Orifice length & $L$ & $0.9 \mathrm{~m}$ \\
Total length of magnetic poles & $L_{\text {pole }}$ & $0.462 \mathrm{~m}$ \\
Length of magnetic pole & $/$ & $0.022 \mathrm{~m}$ \\
\hline
\end{tabular}

As shown in Figure 8, the MR fluids created $45 \mathrm{kPa}$ at $4 \mathrm{~A}$ current input. Thus, the proposed MR damper can produce the required damping force. Also, it is confirmed that the magnetic field is strongly generated at both sides of the coils. The magnitude of magnetic field at coil is almost zero.

\section{Test Results and Discussions}

An experimental apparatus was prepared to investigate the effectiveness of the proposed system, as shown in Figure 2. To measure the acceleration of test mass and the damping force of the MR damper, accelerometers (353B02, PCB Piezotronics Inc.) with 250-g measurement range were attached at the test mass and a load cell (Bongshin Loadcell Co.) was placed between test mass and the MR damper. All measured signals were recorded by pulse measurement equipment (type 3038B, B\&K Co.).

An impact test was conducted to evaluate the performance of the MR damper. The experimental results are presented in Figure 9, specifically, the measured damping force according to the magnitude of applied input currents. From Figure 9, we see that the MR damper met the desired damping properties as set out in Table 2 (i.e., the maximum desired damping force was $805.8 \mathrm{kN}$ at $2 \mathrm{~m} / \mathrm{s}$ and maximum measured damping force was $775.3 \mathrm{kN}$ ). Based on these results, the geometric dimensions of the MR damper were appropriately determined and it is suitable for tuning shockwave profiles. However, the measured damping force results tended to decrease in fast velocity regions. The primary reason for this was fluid dwell time. According to [23], the total shear stress of MR fluid decreases as the fluid dwell time decreases. The dwell time is reduced when high piston velocity is applied to the MR damper.

The measured shock-wave profiles of the test mass are plotted in Figures 10-14. Figure 10 showed the experimental results without current input. Particularly, the behavior of 


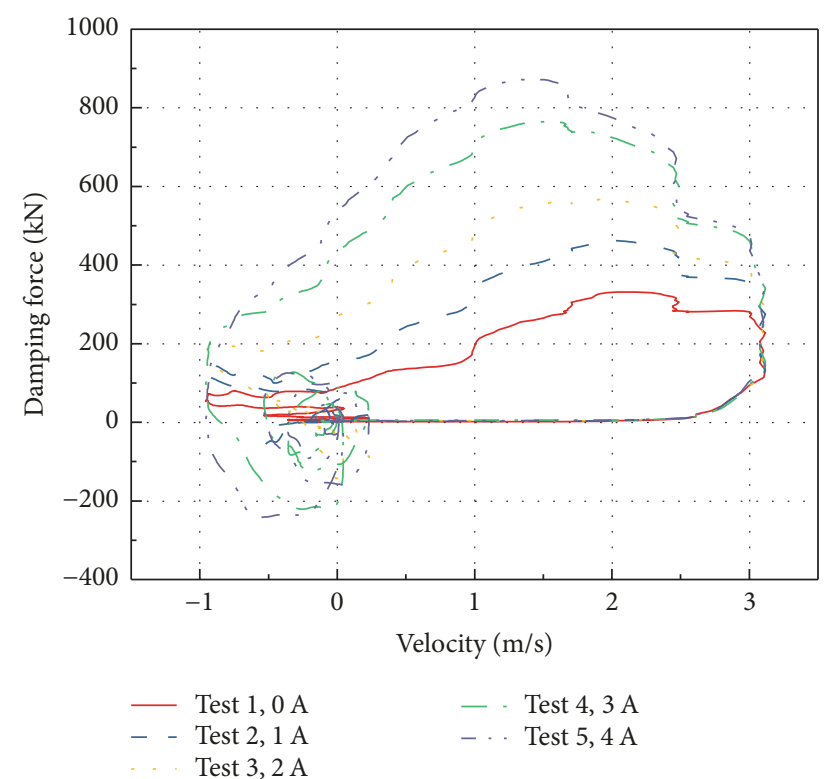

Figure 9: Damping force versus piston velocity.

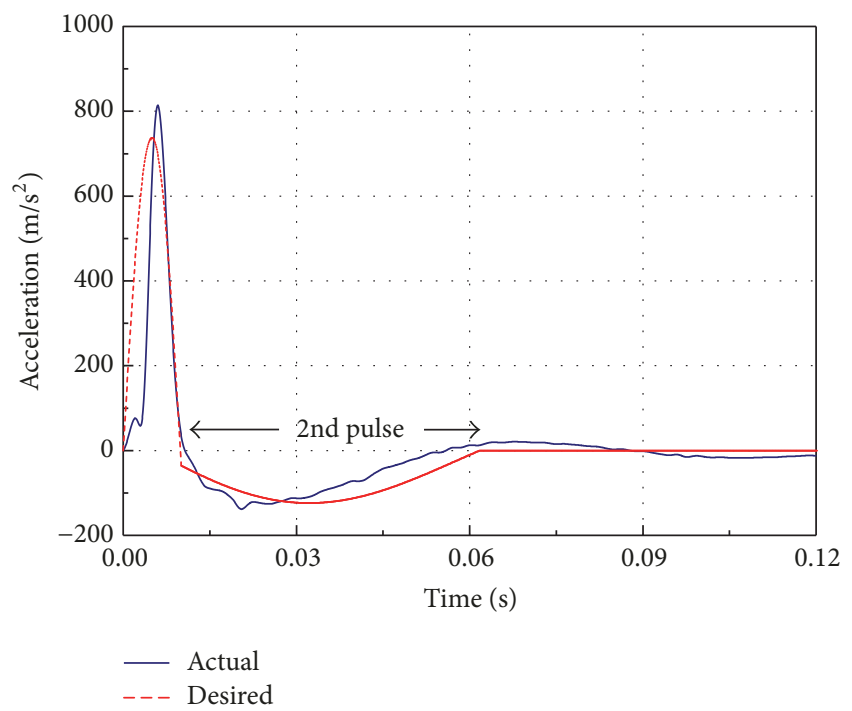

FIGURE 10: Comparison test and simulation results (Test \#1: $0 \mathrm{~A}$ ).

MR damper without current input is almost the same as that of hydraulic damper. Figures 11-13 showed experimental results with several current inputs. Accordingly, it is verified that 2nd pulse changed owing to changes in the magnitude of the input current. The maximum accelerations of 2nd pulse from test $\# 1$ to test $\# 5$ were $141 \mathrm{~m} / \mathrm{s}^{2}, 145 \mathrm{~m} / \mathrm{s}^{2}$, $138 \mathrm{~m} / \mathrm{s}^{2}, 148 \mathrm{~m} / \mathrm{s}^{2}$, and $145 \mathrm{~m} / \mathrm{s}^{2}$, respectively. The duration times of 2 nd pulse from test $\# 1$ to test $\# 5$ were $43 \mathrm{~ms}$, $36.9 \mathrm{~ms}, 53.8 \mathrm{~ms}, 56.1 \mathrm{~ms}$, and $58.9 \mathrm{~ms}$, respectively. The total error rates between desired and measured values were $4.8 \%$ and $11.6 \%$, respectively. The experimental results without particular cases were reasonable for impact testing. However, the duration time results show a substantial difference between desired and measured values; specifically, the desired

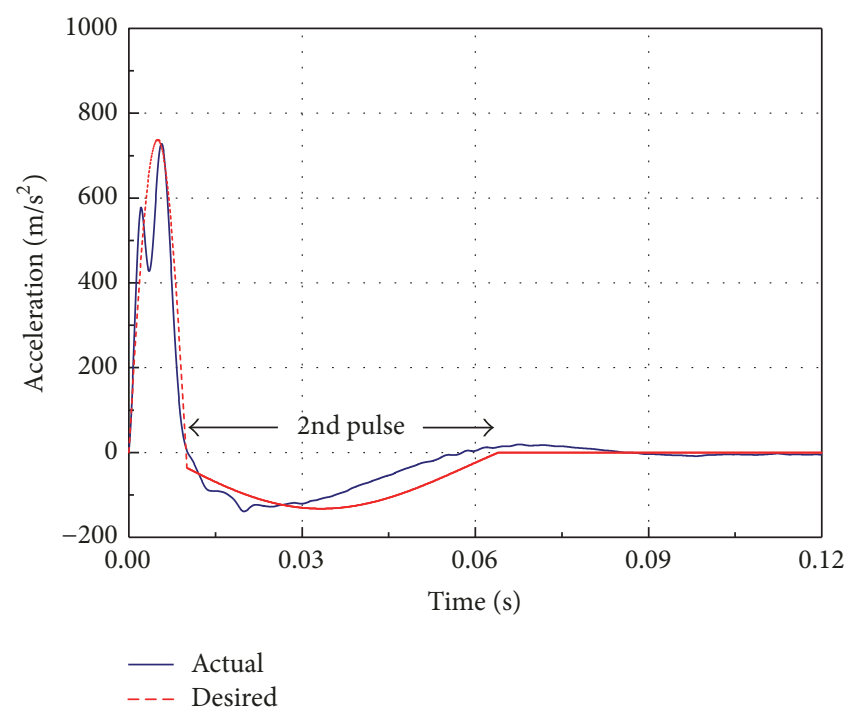

Figure 11: Comparison test and simulation results (Test \#2: $1 \mathrm{~A}$ ).

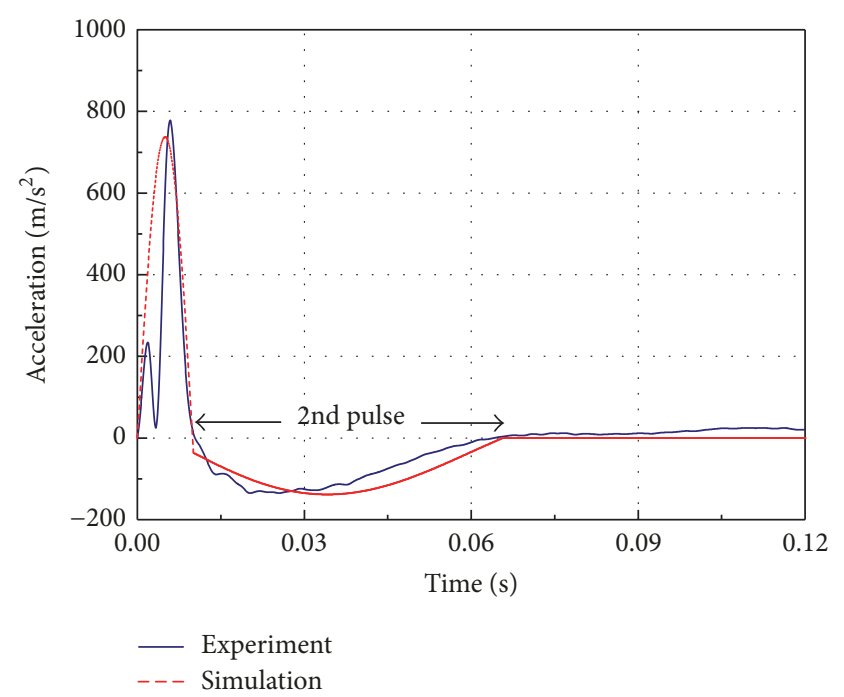

Figure 12: Comparison test and simulation results (Test \#3: $2 \mathrm{~A}$ ).

duration time in the second test was $54 \mathrm{~ms}$ but the measured duration time was $36.9 \mathrm{~ms}$. This was mainly owing to a small damping force in relation to fluid dwell time at the beginning of the 2 nd pulse. Since the transmitted force to the test mass was not effectively reduced, the initial gradient of the measured 2nd pulse was larger than that of desired 2nd pulse. It is obvious that the large gradient of the 2nd pulse reduced its duration time. Another substantial difference was observed in Part III of the fifth test. As shown in Figure 14, Part III of the shock-wave profile shows fluctuations with a maximum amplitude higher than $177 \mathrm{~m} / \mathrm{s}^{2}$. According to [25], the yield stress induced by the input current produced fluctuations in the shock-wave profile (particularly in Part III); there was no such fluctuation in tests 1-4. It is apparent that the cause of the fluctuations was the large input current, such as $4 \mathrm{~A}$. Since the technical novelty of the proposed method is the tunability of the MR damper, the fluctuations 


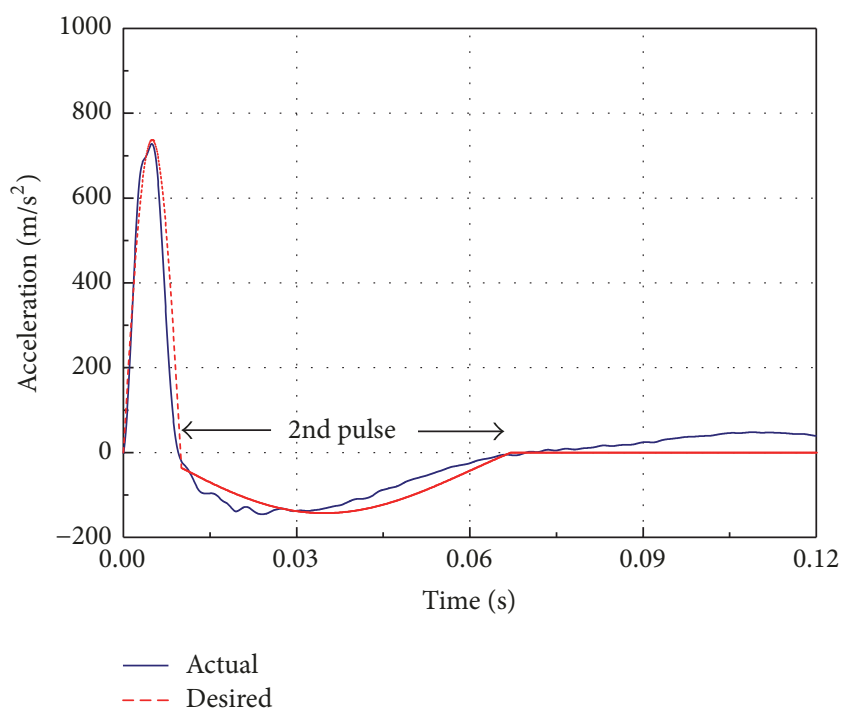

FIgURE 13: Comparison test and simulation results (Test \#4: $3 \mathrm{~A}$ ).

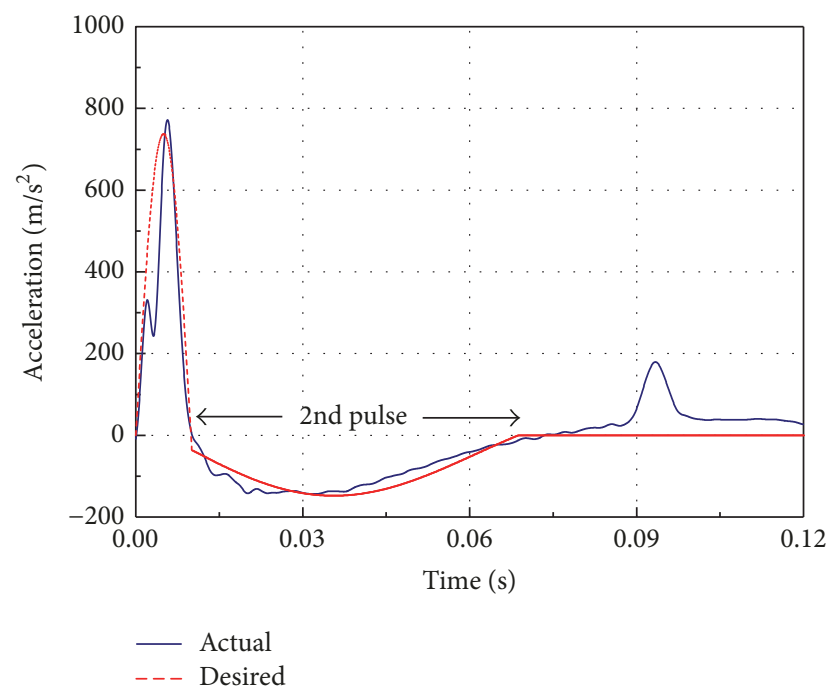

FIgURE 14: Comparison test and simulation results (Test \#5: $4 \mathrm{~A}$ ).

in Part I (owing to the polyurethane spring and velocity generator) were not considered.

\section{Conclusion}

In this work, an impact testing machine system was proposed to experimentally investigate the tunability of dual shockwave profiles. The proposed testing system comprised a velocity generator, impact mass, test mass, spring, and MR damper. The goal of the proposed system was to generate the desired dual shock-wave profiles. Based on this, the damping force of the MR damper was calculated using an annular duct model and a damping force model. In order to evaluate the tunability of the shock-wave profiles (particularly in Part II), five experimental conditions were chosen. According to current input conditions, desired shock-wave profiles can be altered using the MR damper. From the experimental results, it is known that the error rates in 2 nd pulse are $4.8 \%$ and $11.7 \%$. Experimental results clearly demonstrated that the MR damper is effective method for impact testing machine for heavy-weight. In future work, the tuning ability of air spring will be analyzed as a second phase of this research.

\section{Conflicts of Interest}

The authors declare that there are no conflicts of interest.

\section{References}

[1] M. E. Demir, Shock analysis of an antenna structure subjected to underwater explosions [Master dissertation], Middle East Technical University, 2015.

[2] W. Zhaodong, W. Yu, Z. Lei, and D. Jianye, "Modeling and dynamic simulation of novel dual-wave shock test machine," in Proceedings of the In Power and Mechatronics (FPM, 2011), pp. 898-901, 2011.

[3] G. Wang, Y. Xiong, and W. Tang, "A novel heavy-weight shock test machine for simulating underwater explosive shock environment: Mathematical modeling and mechanism analysis," International Journal of Mechanical Sciences, vol. 77, pp. 239248, 2013.

[4] T. H. Kim, C. W. Shul, M. S. Yang, and G. S. Lee, "An analytic investigation on the implementation method for required signal of heavy weight shock test machine," The Korean Society of Mechanical Engineers, pp. 400-405, 2014.

[5] C. W. Shul, T. H. Kim, M. S. Yang, and G. S. Lee, "Development of large-scale heavy weight shock testing system," The Korean Society of Mechanical Engineers, pp. 377-382, 2014.

[6] M. S. Kang, C. W. Shul, T. H. Kim, M. S. Yang, W. K. Song, and G. S. Lee, "A design of large and heavy dual shock generation system," The Korean Society of Mechanical Engineers, pp. 383388, 2014.

[7] H.-C. Kim, Y.-J. Shin, W. You, K. C. Jung, J.-S. Oh, and S.B. Choi, "A ride quality evaluation of a semi-active railway vehicle suspension system with MR damper: Railway field tests," Proceedings of the Institution of Mechanical Engineers, Part F: Journal of Rail and Rapid Transit, vol. 231, no. 3, pp. 306-316, 2017.

[8] W. Jiang, C. Xie, B. Wei, and D. Zhou, "A modified method for risk evaluation in failure modes and effects analysis of aircraft turbine rotor blades," Advances in Mechanical Engineering, vol. 8, no. 4, pp. 1-16, 2016.

[9] E. J. Stone and D. Cebon, "Control of semi-active anti-roll systems on heavy vehicles," Vehicle System Dynamics, vol. 48, no. 10, pp. 1215-1243, 2010.

[10] G. Yang, B. F. Spencer Jr., J. D. Carlson, and M. K. Sain, "Largescale MR fluid dampers: modeling and dynamic performance considerations," Engineering Structures, vol. 24, no. 3, pp. 309$323,2002$.

[11] D.-Y. Lee, Y.-T. Choi, and N. M. Wereley, "Performance analysis of ER/MR impact damper systems using herschel-bulkley model," Journal of Intelligent Material Systems and Structures, vol. 13, no. 7-8, pp. 525-531, 2002.

[12] M. Mao, W. Hu, Y. T. Choi et al., "Nonlinear modeling of magnetorheological energy absorbers under impact conditions," Smart Materials and Structures, vol. 22, no. 11, Article ID 115015, 2013. 
[13] M. Ahmadian and J. C. Poynor, "An evaluation of magneto rheological dampers for controlling gun recoil dynamics," Shock and Vibration, vol. 8, no. 3-4, pp. 147-155, 2001.

[14] M. Ahmadian, R. Appleton, and J. A. Norris, "An analytical study of fire out of battery using magneto rheological dampers," Shock and Vibration, vol. 9, no. 3, pp. 129-142, 2002.

[15] M. Ahmadian and J. A. Norris, "Experimental analysis of magnetorheological dampers when subjected to impact and shock loading," Communications in Nonlinear Science and Numerical Simulation, vol. 13, no. 9, pp. 1978-1985, 2008.

[16] A. L. Browne, J. D. McCleary, C. S. Namuduri, and S. R. Webb, "Impact performance of magnetorheological fluids," Journal of Intelligent Material Systems and Structures, vol. 20, no. 6, pp. 723-728, 2009.

[17] B. Woyski and C. Nelson, "An accurate, repeatable subsidiary component shock test system for the laboratory," in Proceedings of the 75th Shock and Vibration Symposium, vol. 10, pp. 17-22, Virginia Beach, Va, USA, 2004.

[18] R. Boyd, R. Royles, and K. M. M. El-Deeb, "Simulation and validation of UNDEX phenomena relating to axisymmetric structures," in Proceedings of the 6th International LS-DYNA Users Conference Simulation, pp. 9-11, 2000.

[19] M. Christiansen, "Under Water Explosive Shock testing (UNDEX) of a subsea mateable electrical connector, the CM2000," in Proceedings of the Oceans MTS/IEEE - An Ocean Odyssey, pp. 661-666, November 2001.

[20] Z.-Y. Zhang, G.-X. Wang, and Y. Wang, "Numerical modeling of dual-pulse shock test machine for simulating underwater explosion shock loads on warship equipments," Journal of Shanghai Jiaotong University (Science), vol. 14, no. 2, pp. 233240, 2009.

[21] D. Woo, S.-B. Choi, Young Tae Choi, and N. M. Wereley, "Frontal crash mitigation using MR impact damper for controllable bumper," Journal of Intelligent Material Systems and Structures, vol. 18, no. 12, pp. 1211-1215, 2007.

[22] A. Milecki and M. Hauke, "Application of magnetorheological fluid in industrial shock absorbers," Mechanical Systems and Signal Processing, vol. 28, pp. 528-541, 2012.

[23] F. D. Goncalves, M. Ahmadian, and J. D. Carlson, "Investigating the magnetorheological effect at high flow velocities," Smart Materials and Structures, vol. 15, no. 1, pp. 75-85, 2006.

[24] B. Fu, C. Liao, Z. Li, L. Xie, P. Zhang, and X. Jian, "Impact behavior of a high viscosity magnetorheological fluid-based energy absorber with a radial flow mode," Smart Materials and Structures, vol. 26, no. 2, Article ID 025025, 2017.

[25] H. C. Kim, J. S. Oh, and S. B. Choi, “The field-dependent shock profiles of a magnetorhelogical damper due to high impact: an experimental investigation," Smart Materials and Structures, vol. 24, no. 2, Article ID 025008, 2014. 


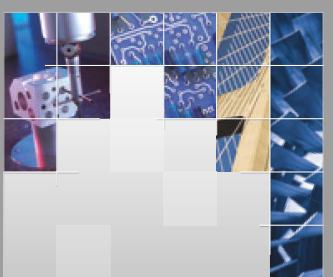

\section{Enfincering}
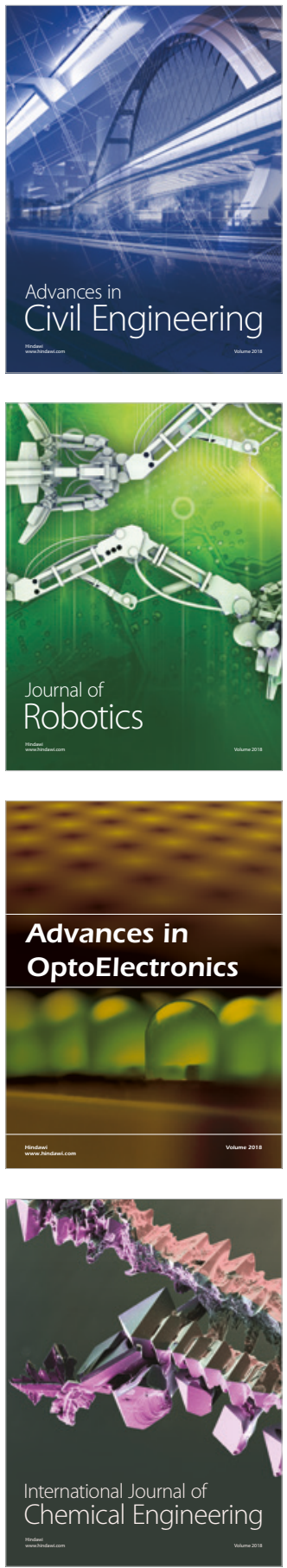

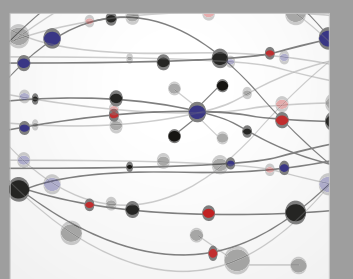

\section{Rotating \\ Machinery}

The Scientific World Journal

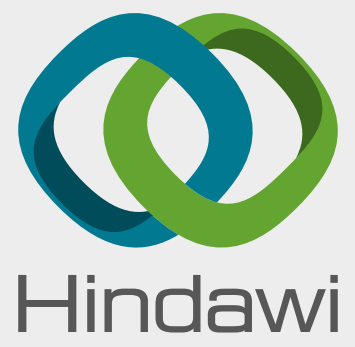

Submit your manuscripts at

www.hindawi.com
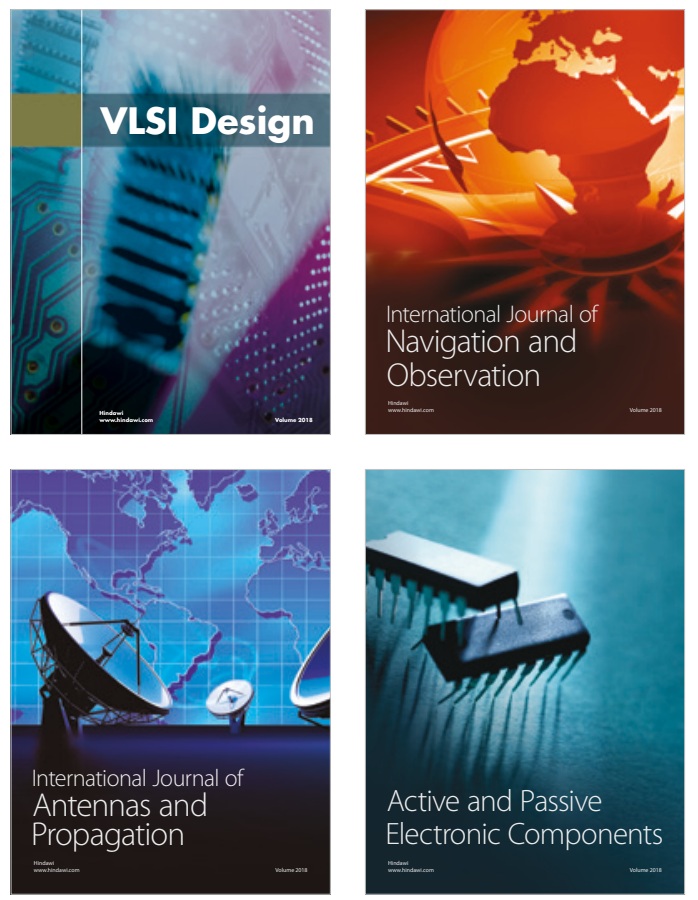
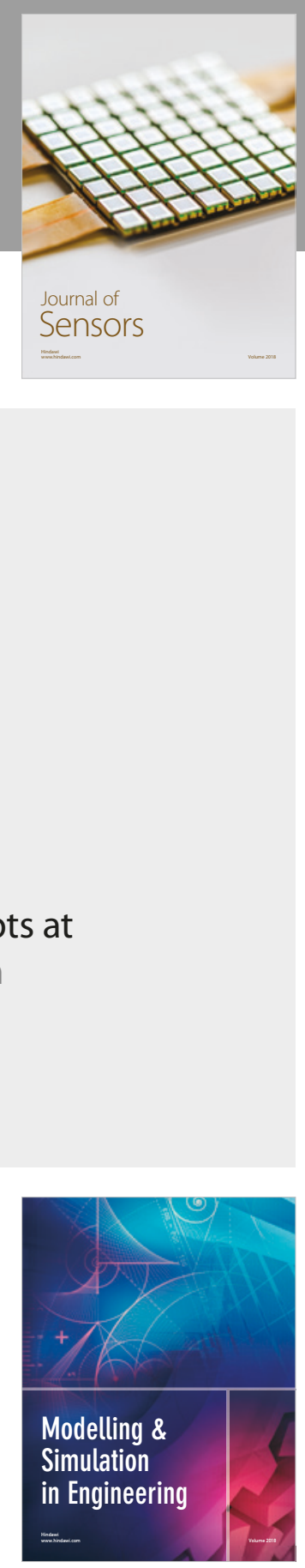

\section{Advances \\ Multimedia}
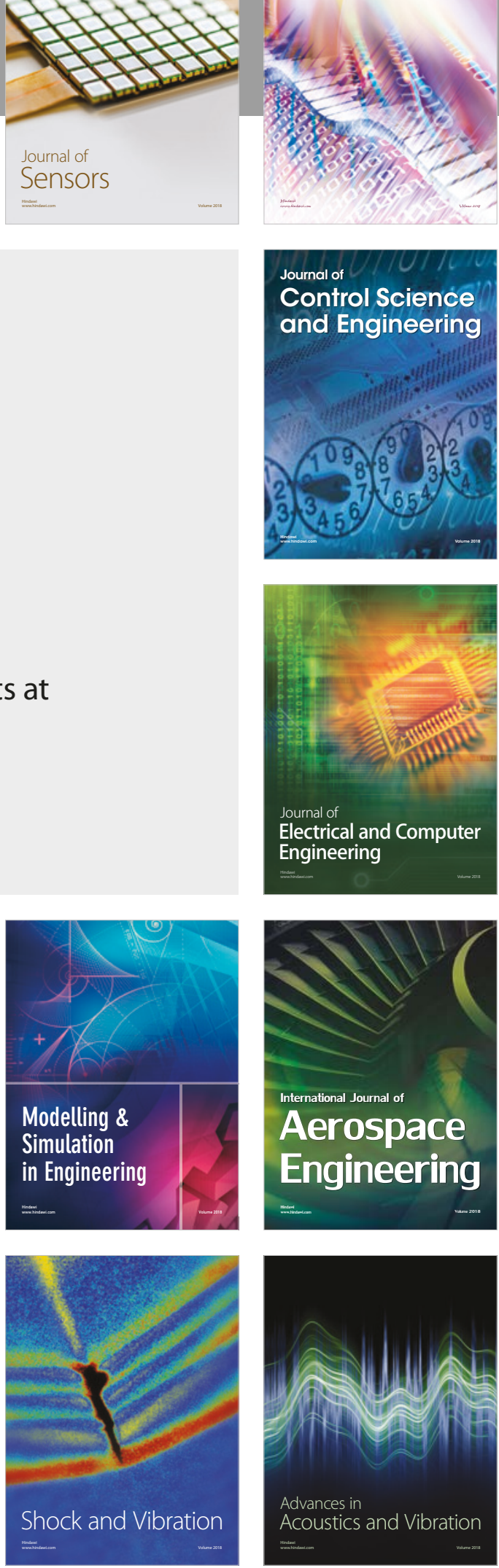